\title{
Managing Transitions: Coping Strategies for New Principals in Colleges of Education, Ghana
}

\author{
Caroline Aggrey-Fynn
}

Accra Institute of Technology

\begin{abstract}
Principals' transition in Colleges of Education in Ghana is critical to quality teacher education and training, but it comes with complexities and challenges to newly appointed principals. However, there is a seeming absence of research on strategies for smooth transitions in Colleges of Education in Ghana. This study was therefore conducted to establish strategies that promoted the College of Education principals' transition management in Ghana. Phenomenological research design was used for the study. Ten (10) newly appointed principals of public colleges of education were purposively sampled for the study. Interview protocol was the research instrument used. The data collected was analyzed using content analysis method. The study established that capacity building, relationship building, appropriate leadership style and maintenance of discipline were key among the coping strategies for smooth transitions. This study then provides a guide for new principals. It was recommended that this area should be further explored and a model for managing transition designed to support College of Education principals' in transition.
\end{abstract}

Key words: strategies, Principals, experience, transition, leadership, administrative,

\section{Introduction}

Dewey (2012) was of the view that naturally individuals are anxious about transition and its implications for their particular role or job. Similarly, Burkhauser et al. (2012) examined actions and perceived working conditions of principals in their first-year. The authors noted that principals who are new to their schools face a variety of challenges that could influence their possibility of improving their schools' performance and retaining the principalship. They indicated that there is limited research on first-year experiences of principals to clearly understand the issues and efforts to promote school improvement. Abdulai (2012), Atiku (2013), Newman, 2013, Nyarkoh (2016); Osei and Adu (2016) investigated challenges encountered in colleges of education in Ghana but they did not explore the strategies for smooth transitions. The interest of this study is to investigate strategies for smooth transitions in the context of the college of education principals in Ghana during the first year in the role.

\section{The Problem Statement}

Considering coping mechanisms for successful transitions, Cockley (2011) noted that the first year as principal is a learning process. The first year is to learn about oneself using one's core values to help guide decision-making and goal-setting; get oneself ready for the principalship; find the right "fit" regarding oneself and one's position; and know what the expectations are. Obviously, these ideas could support principals in transition. Dewey (2012) contends that each establishment has its own distinct environment related to transition. Again transitions are limited by support and job specific models (Frankovelgia, 2010). Consequently, investigating country and position specific strategies for smooth transitions in the case principalship is warranted. Thus, this study makes a significant contribution to literature on strategies that can improve transition management of college of education principals in Ghana. The research question that guided the study was:

What suggestions can help in promoting effective transition management practices of new principals of Colleges of Education in Ghana? 


\section{Literature Review}

Preparing leaders for transition is very important in view of assertion that everyone involved in a transition requires training, preparation and different approaches (Bagi, 2016; Dewey, 2012) and gaining a wide range of leadership experience and skills within schools to manage it (Bagi, 2016) because such periods are usually seen as chaotic, disruptive, and full of uncertainties (Dewey 2012). It also involves periods of destabilization with "times of reduced performance and vulnerability to outside forces", yet they are often under invested and not well planned in organizations. This is particularly common in leadership transitions at the highest level (Dewey, 2012). Therefore, the knowledge and skills gained through the preparation for a smooth transition can be supplemented by continuous training, mentoring and support to give the principals a powerful start and further encourage and support them throughout their tenure (Bagi, 2016).

Similarly, Opeyemi (2013) established the need for training school principals before engaging them. He argued that leadership preparation for school principals through certification is important for school improvement in that it will facilitates principals' effectiveness. The untrained leader may not know what is ahead and how to surmount certain hurdles on the job. Certifying principals before engaging them could be a laudable suggestion and this would put incoming principals on their toes. Studies suggest that those individuals who participated in the principal readiness education program demonstrated statistically significant gains in principal self-efficacy as compared to non participant group (BexarPREP, 2012). This clearly buttresses that offering pre-service training is paramount before putting principals on the job as suggested by the Wallace Foundation (2012). Also, Wallace Foundation emphasised monitoring.

Bagi's (2015) also identified pre-commencement experiences in the school, efficient reception and induction, supportive and proactive school board, mentoring and support from other principals, and independent school associations as significant elements that helped the principal to make a good start in the transition in the role. Research found that one factor that is critical to successful leadership transitions is establishment and alignment of expectations (Hill, 2003; Neff \& Citrin, 2005; Watkins, 2003). Hill (2003) noted that, "One of the most important organizational tasks managers face is developing and working through shared expectations about roles, goals, and priorities with their subordinates' (p. 120). Department for Education and Skills (2004) also emphasized the need for creating a shared vision, strategic plan, collaboration and links with other institutions was important for the leader. These help to align expectations.

Neff and Citrin (2005) found that due to misaligned expectations, numerous leadership transitions are negatively turbulent. They recommended that if "different perspectives do not align, you [the leader] will be setting off on a path marked by misunderstanding, anxiety, tension" and all too often failure" (Neff \& Citrin, 2005 p. 48). A new principal should get immersed in the culture of a school for better understanding before forming long term goals and plans to prevent errors (Schein, 2010; 1999). Hence, socio-cultural issues of new school principals cannot be generalized until it delved into.

Furthermore, Cockley (2011) noted that in the first year of transition, new principals should establish relationships and trust with staff members, students, central office administrators and the community and open up good lines of communication with them. New principals should understand their strengths and weaknesses. They should be visible and available to all particularly students for social and emotional support (Cockley, 2011). Communities want the best education for the young ones, and will strive to support through established rapport (Cockley, 2011). The conclusion is, as a new principal one should stay in touch with the community. The principal should work collaboratively with administrative team and other administrators including central office administration and understand the expectations of the superintendents (Cockley, 2011). A new principal should understand how teams work at that level, and why they are beneficial and provide adequate logistics (Cockley, 2011).

Cockley (2011) and Afful-Broni (2006) also emphasized on effective discipline. Afful-Broni (2006) found out that in Ghana sometimes tertiary student leadership tend to argue with disciplinary committees. They argue that some aspects of discipline tramples on their human rights. These notwithstanding, Afful-Broni stated, "School leaders must be strong and equivocal to spell out "what schools are for, what is essential, 
what can be avoided and what may be omitted" to promote effective school discipline and "peace of mind and happiness". Student leaders must also be held accountable for students' misbehaviour particularly when the culprit absconds (Afful-Broni, 2006, p. 224).

Cockley (2011) asserts that a new principal should provide a positive perspective and significant focus on data at the onset of principalship. This affirms Afful-Broni's (2006) argument that educational leaders should recognise that school data is very necessary and handling it with outmost care seems beneficial to the school. The importance of data including reviewing the data to learn about the school and relying on it to support and highlight academic priorities is also stressed (Afful-Broni, 2006).

Also, leadership style is very essential, in that it actually directs how the new principal in transition runs the institution (Cockley, 2011). Allen (1998) identified autocratic, democratic and laissez-faire leadership styles. He theorized that unless leaders can adapt their leadership style to suit demands of their environment, leaders may not be effective even with excellent diagnostic skills. This is based on the assumption that there is not one single ideal approach to leading because circumstances vary (Fiedler, 1967, cited in Cole, 2004). This creates a gap to investigate leadership styles employed by College of Education principals to enhance smooth transitions but it is not the focus of this study.

Furthermore, studies stressed the importance of mentoring and coaching for new/beginning principals in transition (Bagi, 2015; Duncan \& Stock, 2010). Similarly, other studies revealed that a new principal should find a mentor and seek collaboration with others for information, counsel and encouragement (James-Ward, 2013; Cockley, 2011). A new principal should find one who is trustworthy and comfortable to be with. $\mathrm{He} / \mathrm{she}$ should communicate effectively with outgoing principal and seek information on policies, procedures, routines, structures, and how things worked (Cockley, 2011). Also, being a member of a professional group comes with prospects as professional growth and support in times of need (Cole, 2004). In view of the discussion so far, the importance of transition management in terms of coping strategies to new principals cannot be overemphasized. Realistically, several strategies are available per the earlier discussed views. However, the contention is "are the coping strategies available in the Ghanaian setting?" This is worth investigating.

\section{Research Methodology \\ Research design}

The phenomenological research design was used for the study. This was due to its ability to provide opportunity to delve into and understand the principals' lived experiences as far as transition management coping strategies were concerned.

\section{Sample and Sampling Procedure}

Purposive sampling was adopted to select ten (10) out of 46 principals from public colleges of education. Only 10 new principals were accessible for the study.

\section{Research Instrument}

The instrument used for the data collection was a self-designed interview protocol. The items were openended and this was to help explore further the issue studied.

\section{Data Collection Procedure}

I sought permission appropriately from the president of the Principals' Conference (PrinCof) to facilitate the data collection. I established rapport with the participants via telephone and face-to-face conversations to create frank and open discussion throughout the data collection process. An electronic mail (e-mail) which spelt out the rationale of the study and the area of interest was sent to the 10 respondents. This pre-informed the respondents on the nature of the interview. The duration for data collection was five days. The degree of contact with each respondent was approximately 45 minutes. The interview progressed systematically with probes for elaboration and in-depth data. Creswell's (2007) ethical considerations for data collection were employed. 


\section{Data Analysis}

Thematic content analysis was used to analyse the data. The data was transcribed, organized into themes and coded manually. Microsoft Excel was used to determine which themes occurred most or least. The result was then written in accordance with themes that emerged.

\section{Results}

In all, the data from the 10 principals (respondents) were analysed and presented in themes with significant quotes in respect of the research question. Basically, the categories of suggestions and their corresponding respondents in brackets include: demand comprehensive handing over notes (3), adopt appropriate leadership style (7), capacity building (10), relationship building (10), ensure discipline (7), motivation (2), monitor and ensure adequate data management (3), and provide adequate logistics (2).

\section{Comprehensive Handing Over Notes}

With respect to comprehensive handing over notes, the respondents explained that every necessary information about the college should be clearly stated in the handing over notes. Here are quotes per the 3 respondents:

\footnotetext{
"The handing over notes should be very extensive. It should cover every aspect of the administration." (Roke)

"Make sure the handing over notes touches all areas of college administration." (Kum)

“... So handing over notes must be comprehensive enough otherwise demand to know more." (Pon)
}

\section{Adopt Appropriate Leadership Style}

Seven (7) of the principals suggested that new principals should adopt appropriate leadership style with individuals stating specifically what they meant by that. One respondent mentioned that open administration style of leadership will enhance rapport, approachability and communication and trust. Quote from the respondent:

\section{"Do your work in such a way that everybody can approach you. Open door administration. When something is wrong they will prompt and support you." (Bec)}

As part of leadership style, a strategic plan should be in place. Two of the respondents who noted this described it as devising a plan that spells out the vision and methods to achieving it. Quotes:

\section{"There should be a strategic plan. That is the first. That will serve as a guide for the transition." (Pon) \\ "Principals should have their vision outlined, well organized and set out a plan to implement them. Involve stakeholders' roles and let them buy into it." (Mom)}

Two respondents indicated that new principals should not rush to make changes in the transition as it could mar one's administration. Significant quotes are:
"... there is no need to rush. One to two months could also be used to study the system before you effect changes." (Mom)
“Don't just start imposing fresh ideas. Proceed gradually to help you be a good manager.” (Soko)

Three of the respondents explained that new principals should be exemplary leaders for their subordinates to follow suit otherwise they may not be effective. Quotes are:

\footnotetext{
"When you are leading, people look up to you so you should set an example as Paul will say to Timothy to be an example to his peers." (Sle)
} 
"You should also be a leader by example that they follow suit otherwise they may not be up and doing." (Ace)

"Set good examples. If you do that everybody will rally behind you." (Pon)

All inclusive administration was also suggested by five (5) respondents. Quotes are as follows:

"Get all hands on deck to ensure that the college culture within the formal and informal modalities prevails." (Mom)

"Use committees. It makes actions more transparent. In my case, the cooperation of the staff was phenomenal ... the enthusiasm shown by some of them was commendable." (Sle)

“Deliberate with staff and seek guidance." (Pon)

"Depend on others. ... I always say no one is perfect, you may know everything but certainly others have other positive talents to compliment yours." (Bec)

"To have activities carried out appropriately. Delegate appropriately. This will help work towards achieving set goals." (Ace)

Two respondents stated the need to be unpredictable. This was explained as not allowing people to guess your intensions or read your mind. You should vary your actions and attitudes. Quotes from the code are as follows: "Be unpredictable, it prevents students and staffs from planning their lives around
your movement." (Bec)

"Don't give them the chance to guess your next line of action." (Pon)

Two (2) other respondents noted that principals should be effective communicators. They implied that information should be shared and it should be clear and precise for all to understand. Here are quotes from the respondents:

"The leader must also learn to listen and to communicate more effectively. Be loud, clear and precise." (Bec)

"Let everyone be in tune with college plans and activities." (Buri)

\section{Capacity Building}

Capacity building was identified by all the 10 respondents as one of the strategies that could be adopted to help new principals cope with transitions. Two respondents described capacity building as exploring and updating knowledge on leadership styles. That was to suggest what leadership style to adopt for effectiveness and efficiency. Quotes from the code are as follows:

"Avail yourself to training in areas of leadership styles to suggest what leadership style to adopt ... In short, acquire the habits of smart leader. Be above reproach." (Mom)

"Should work towards it. ... Read courses that relate to leadership and leadership style ... so that you prepare towards the position." (Buri)

Six respondents explained capacity building as obtaining broad knowledge in the field. Significant quotes from the code are as follows:

"You must know more about teacher education. Attend workshops ... Talk to other principals and tap from their experiences." (Mom) 
“... But I think for any individual to head such a place you should have a sound knowledge of the teacher education program." (Buri)

"You must be above the people you are leading otherwise or they will lead you. So first, you must be knowledgeable and on top of your job." (Sle)

"If you don't have broad knowledge in this field it will be difficult to manage it. Learn more. Attend workshops, conferences, etc." (Krop)

"They should also attend academic and other equally good conferences to broaden their knowledge ... Gather a lot on the College of Education landscape." (Ace)

"Before you assume office ... enroll for the Human Resource Management course to boost your personnel management skills." (Soko)

Other respondents (6) agreed that one thing that was lacking for new principals was orientation. They suggested that the college council plans and organizes well structured orientation that contains adequate knowledge on educational leadership and the College of Education system for new principals. Quotes from code are:

"The issue of orientation is not working. Before you realize they have messed up ... impress upon the appropriate bodies to organize proper orientation for you." (Kum)

"They should be given orientation as soon as they are appointed but here nothing will be done until things go bad. ... They should be given orientation on the dos and don'ts." (Krop)

"What is lacking is orientation ... Immediately, there should be some orientation to usher in the new leaders." (Ace)

"I think the first thing they need to do is orientation. ... Because most of us come in without really knowing what to do ...” (Bec)

"They should also be taken through some orientation to expose them to College of Education system." (Soko)

"Adequacy of Knowledge on educational leadership is limited. They need orientation to facilitate smooth transition.” (Mom)

Staff capacity building was not marginalized. One principal laid emphasis on staff development as a priority area for the new principal. This was expressed as giving staff training to update their knowledge and enhance their quality and capacity for job delivery. Quote from the respondent:

"Staff development is a priority. They will work better ...It will boost participation.

Exhaust all available means to sponsor staff development programs." (Mom)

Five (5) respondents described capacity building as studying the terrain by reading through files to understand and uphold the 'status quo' to avoid failure. Here are quotes from the respondents:

"A system is already in place. As a new principal, take time in studying the terrain ... Knowing how the system works the principal can go on gradually.” (Soko)

"The new principal has to understand the mission and vision of the institution. ... you should be able to maintain the desired standards." (Ace)

"There is nothing like a model for you as a new principal ... So, you must study the terrain very well to know the culture or you could mess up." (Bec) 
"Delve into the records to know more about the college. Acquaint yourself with the system and monitor." (Pon)

"You must be able to study the culture of the people you are leading to know and manage them." (Sle)

\section{Relationship Building}

The respondents suggested that new and aspiring principals should build good relationship with their stakeholders. Six (6) respondents explained relationship building as establishment of rapport with staff and students in order to live in harmony. Relevant quotes are as follows:

"Relate well with everybody in the college and what you don't even expect, they will do to make your work easier”. (Bec)

"So, it's about having time for the work and making sure that you do the work well with a good rapport and relationship ... Also, when students are doing something, you must show interest ... If you keep your distance, they'll also not mind you." (Sle)

"Be interested in students' programs and honour their invitations." (Ace)

"Misinformation is killing the system. Overlook that and establish rapport." (Roke)

"Don't come with prejudice. Be magnanimous. Don't have political parties factions ... If you play that well things will be better for you." (Pon)

"When students invite you to their programs and you don't attend they will not be happy so if you can't attend, delegate someone to represent you." (Mom)

Two (2) respondents described relationship building as staying in touch with people in their respective communities since the colleges are situated in larger communities. Here are corresponding quotes from respondents:

"Initiate moves to perpetually to be abreast with the community issues ... Get the community involved in college activities. ... However, let them understand the broader objective of education so that the college is not unduly influenced by the community." (Mom)

"Stay in touch with the community people and the college council, Share your vision with them. If you have their approval then you can implement it." (Mom)

The respondents also noted that to build relationships, the new principals should also stay in touch with National Council for Tertiary Education (NCTE). Per all the ten (10) respondents, building relationships with NCTE was necessary owing to its special role in teacher education in Ghana. Quotes from respondents are:

"NCTC is responsible for regulating our level. If you don't work with them, you may not understand the system." (Kum)

"Let me mention NCTE. To succeed, please acknowledge that institution. It controls and regulates all affairs of the colleges." (Buri)

"Call NCTE when you are not sure of available policies. They'll explain everything." (Ace)

"There's a coordinator responsible for Colleges of Education. Visit the office for information." (Krop) 
"Go to NCTE for help. The coordinator there will certainly assist." (Bec)

"If you fall on the coordinator at NCTE he'll guide you." (Pon)

"Fall on NCTE. They have lots of support for principals even though not enough." (Sle)

"NCTE controls the colleges. Let them explain how the system runs." (Roke)

"Attend programs and workshops organized by NCTE. These will guide you through the transition." (Mom)

"When you are invited to NCTE meetings do well to attend personally." (Soko)

Additionally, all the ten (10) respondents described relationship building as staying in touch with college council. The respondents' views on staying in touch with college council meant that the new principal must work with the council in harmony. Quotes from the code are:

"If college council is in place, I'll advice you report to them ... their support is critical. If I didn't have their backing, my administration would have failed. Give them update on college activities." (Roke)

"Make sure you work diligently with the council. If you skip them they'll frustrate you. (Pon)

No action can be taken without council approval so consult them and work with them. (Buri)

Constantly present your report on college activities to the council." (Soko)

"Stay in touch with the college council, particularly the chairperson. Establish rapport. (Ace)

I would like to recommend that if new principals are appointed, they should be appointed they should respect the council in all areas." (Kum)

"Oop! The college council is sitting tight. They are responsible for college effectiveness. Always consult them for their inputs and support." (Sle)

"Share your vision with the council. If you have their approval then you can implement it. (Mom)

The college council should have a say what goes on within so let them know what you have to offer." (Krop)

"Relate well with the council and make conscious effort to update them on issues in the college." (Bec)

“Don't marginalize your council.” (Kum)

Two (2) respondents noted that the new principals should identify with the Principals' Conference (PRINCOF) as a way of building relationship with all other principals. PRINCOF is a principals' position specific group that monitors and provides support for members. Thus, one's membership will attract immense benefits. Corresponding quotes are:

"I found PRINCOF very valuable. The meetings and conferences really guided me.

So, I'll advice every principal joins and makes use of PRINCOF." (Ace) 
“Being a member of PRINCOF, you'll be protected. You'll be guided, and you'll be well supported." (Sle)

\section{Ensure Discipline}

Three (3) respondents emphasized that discipline should be established and maintained. This was explained as maintaining law and order through empowering the SRC. Significant quotes are:

"Train the SRC to understand the college rules and regulations.

They'll make sure students obey." (Ace)

"Talks with student leadership and entire student body can help shape their mindsets." (Kum)

“'Organize leadership programs for the Students' Representative Council to equip them for their roles in achieving discipline."

(Mom)

However, three respondents stated that to ensure discipline, the new principal should be cautious about misinformation gossips and backbiting. Relevant quotes are:

"... some of the staff will come and say all sorts of things for favor. Open your door for productive discussions and not gossips and backbiting." (Roke)

"Don't just condemn or accept issues as presented to you. Investigate and do a thorough analysis and make your own informed judgments." (Ace)

"Because of favors some may turn themselves into informants. Do not act on hear say ... be observant otherwise there will be cases and that may undermine ones administration." (Soko)

\section{Ensure Motivation}

The two respondents described motivation as giving staff incentives and inspiration as a drive to enhance work output. Significant quotes are as follows:

"Motivation is very important. It is not about money alone, but their involvement in activities. Make sure whatever is due them goes to them. Currently, there is the GETfund staff development allocation encourage staff to tap into the financial support." (Ace)

"Motivate students and staff to be committed to their responsibilities." (Mon)

\subsection{Monitor and Ensure Adequate Data Management}

Three respondents explained that new principal should make sure that all college data are well managed for efficiency and effectiveness. Here are corresponding quotes:

"Ahaa! Yes! College data. Be very particular here. If your data is not well managed, you'll fail. You can't do any good planning." (Kum)

"Make sure everything is filed otherwise auditors will drag you to court." (Krop)

"Monitor how they handle data. Let the right people keep that, and that's the college secretary." (Bec)

\subsection{Provision of Adequate Logistics}

Provision of adequate logistics was explained by two respondents as making all resources available. This could be done through needs assessment and frequent maintenance of available logistics to ensure effectiveness and efficiency. Quotes from the code are:

"There should be adequate supply of logistics. Frequent maintenance of available logistics such as vehicles ... for efficiency." (Mom) 


\section{"Make all resources available to them through needs assessment and not just by departments. Stay transparent." (Ace)}

\subsection{Discussion}

On strategies for smooth transitions, literature affirms the findings of this study. The new principal should adopt appropriate leadership style in transition (Cockley, 2011) as circumstances vary (Fiedler, 1967, cited in Cole, 2004). Everyone involved in a transition requires Capacity building (Bagi, 2015; Cockley, 2011; Dewey, 2012), ongoing professional development for self and staff (Bagi, 2015; Cockley, 2011; Opeyemi, 2013) and a wide range of leadership experience within schools to manage it (Bagi, 2015). These are needed due to the probable chaotic and disruptive nature of transitions (Dewey, 2012).

Regarding relationship building, Cockley (2011) emphasised the need for new principals to build good relationship with their stakeholders by staying in touch with people in their respective communities and constituents. They should be visible and available, get to know the students and other constituents for social and emotional support. Cockley notes that this requires trust with staff members and stakeholders as well as open and clear lines of communication. Furthermore, with good public relations, there could be formal and informal dialogue with key community individuals on issues concerning the school and vice versa to meet the students' needs. Communities want the best education for the young ones, and will strive to support. Department for Education and Skills (2004) also, mentioned the importance of creating a shared vision, strategic plan, links and collaboration with other institutions.

Research contends that other factors other than solely leadership contribute to school performance and improvement (Afful-Broni, 2005). This probably explains why a factor critical to successful leadership transitions is establishment and alignment of expectations (Hill, 2003; Neff \& Citrin, 2005). Non-alignment of different perspectives could lead to "misunderstanding, anxiety, tension and all too often failure" (Neff \& Citrin, 2005, p. 48). In effect, as a new principal, this can be addressed when he or she is in touch with the stakeholders and understands the culture. This concept of being in touch is considered throughout probably because the college could not live in isolation. This affirms the strong need for collaboration to control and enhance students'/school achievement.

Joining a group comes with benefits including opportunities for professional growth (Cole, 2004). Provision of adequate logistics (Cockley, 2011), studying and maintaining the culture (Cockley, 2011; Schein, 2010), mentorship (Cockley, 2011; Duncan \& Stock, 2010; James-Ward, 2013), Monitoring (Cockley, 2011; Wallace Foundation, 2012), and motivation are required for effectiveness and efficiency. Again research affirms the need to ensure discipline to control misbehaviour (Afful-Broni, 2006; Cockley, 2011) to minimise problems particularly in Ghana where leadership training for prospective school leadership is rare (Afful Broni, 2006). Obviously, the Harmonised Statutes for Colleges of Education (NCTE, 2015) is available. However, they do not provide enough information to guide particularly the novice principal through transitions.

\section{Conclusions}

The findings of the study established strategies which new principals could adopt to promote smooth transitions. The key strategies included, capacity building, relationship building with all stakeholders, adopting appropriate leadership style, and ensuring discipline by maintaining law and order. Other coping strategies were effective monitoring, demanding for comprehensive handing over notes to have a better understanding of the new environment, adequate data management for smooth planning and plan implementations, provision of adequate logistics to promote effectiveness and efficiency in work execution and motivation to enable all involved develop passion and interest for improved performance. This study then provides a guide and hope for aspiring and future Ghanaian college of Education principals who may encounter leadership transitions. It was recommended that a census study should be explored and a transition management model designed to support College of Education principals for smooth transitions.

\section{References}


[1] Abdulai I. A. (2012) Administrative challenges encountered at Accra College of Education. Retrieved on March 1, 2019 from https://erl.ucc.edu.gh/jspui/bitstream/123456789/2609/1/ABDULAI\%202012.pdf.

[2] Afful-Broni, A. (2006). Theory and practice of educational leadership in Ghana. Accra-Ghana: Yamens Press Ltd.

[3] Allen, G. (1998). Supervision. In A. M. Maslanka (Ed.). Evolution of leadership theories (pp. 7-8.). Allendale, Michigan: Grand Valley State University Press.

[4] Atiku, B. A. (2013). Transitional challenges facing colleges of education in the Volta Region of Ghana. University of Cape Coast, Cape Coast. An unpublished M.Phil thesis.

[5] Bagi, S. (2015). Journeys into principalship: The experiences of beginning principals of independent schools. Griffith University. An unpublished $\mathrm{PhD}$ thesis.

[6] BexarPREP (2012). Who is preparing school leaders to transition into the job of urban school principal? Analyzing the impact of a regional principal readiness education program on principal self-efficacy. Retrieved from

https://www.esc20.net/upload/page/1092/docs/bexarPREPmanuscript.pdf

[7] Burkhauser, S., Gates, S. M., Hamilton, L. S. and Ikemoto, G. S. (2012). First-year principals in urban school districts: How actions and working conditions relate to outcomes. Retrieved from https://www.rand.org/pubs/technical_reports/TR1191.html.

[8] Cockley, K. R. (2011). The transition experience: The first 100 days of the middle school principalship. Kent State University. An unpublished Ph.D. thesis.

[9] Cole, G. A. (2004). Organizational behavior, theory and practice. UK: Thompson learning.

[10] Creswell, J. W. (2007). Qualitative enquiry and research design: Choosing among five approaches. California: Sage Publications, Inc.

[11] Department for Education and Skills (2004). National standards for headteachers. Nottingham, U.K.: National Archives. Retrieved on December 18, 2017

http://webarchive.nationalarchives.gov.uk/20130401151715/https://www.education.gov.uk/publicati ons/eOrderingDownload/NS4HFinalpdf.pdf

[12] Dewey, B. I. (2012). In transition: The special nature of leadership change. Journal of Library Administration, 52(1), 133-144.

[13] Duncan, H. E., \& Stock, M. (2010). Mentoring and coaching rural school leaders: What do they need? Mentoring \& Tutoring: Partnership in Learning, 18 (3), 293-311.

[14] Fiedler, F. E. (1967). A theory of leadership effectiveness. In G. A. Cole (Ed.), Organizational behavior, theory and practice (p. 202). UK: Thompson learning.

[15] Frankovelgia, C. (2010). The key to effective coaching. Retrieved on June 12, 2018 from: https://www.forbes.com/2010/04/28/coaching-talent-development-leadership-managingccl.html\#6c36e09238e0

[16] Hill, L. A. (2003). Becoming a manager: How new managers master the challenges of leadership. Boston: Harvard Business School Press.

[17] James-Ward, C. (2013). The coaching experience of four novice-principals. International Journal of Mentoring and Coaching in Education, 2(1), 21-33.

[18] National Council for Tertiary Education (2015). Harmonized statutes for colleges of education. Accra: National Council for Tertiary Education.

[19] Neff, T., and Citrin, J. M. (2005). You're in charge - now what? The 8 point plan. New York: Crown Business, a division of Random House.

[20] Newman, E. K. (2013). The upgrading of teacher training institutions to colleges of education: Issues and prospects. Retrieved from https://journal.lib.uoguelph.ca/index.php/ajote/article/view/2728/3129.

[21] Nyarkoh, E. (2016). The degree of autonomy in colleges of education in Ghana: A comparative study of before and after their upgrade to tertiary status. University of Oslo. An unpublished PhD thesis.

[22] Opeyemi, D. (2013). Leadership preparation for school Principals: The place of certification. Retrieved from www.google.com.

[23] Osei, A., \& Adu, K. O. (2016). Transitional challenges facing staff development in selected colleges of education in Ghana. International Journal of Research in Economics and Social Science, 6(4), 301-315. 
[24] Schein, E. H. (2010). Organizational culture and leadership (4 ${ }^{\text {th }}$ ed.). San Francisco: Jossey-Bass.

[25] Schein, E. H. (1999). Process consultation revisited: Building the helping relationship. Reading, Mass: Addison-Wesley.

[26] Wallace Foundation (2012). The making of the principal: Five lessons in leadership training. Retrieved from https://portfolio.du.edu/ downloadItem/327192. 